\title{
Uncertainty Increases Pain: Evidence for a Novel Mechanism of Pain Modulation Involving the Periaqueductal Gray
}

\author{
Wako Yoshida, ${ }^{1,3}$ Ben Seymour, ${ }^{1,4}$ Martin Koltzenburg, ${ }^{2}$ and Raymond J. Dolan ${ }^{1}$ \\ ${ }^{1}$ Wellcome Trust Centre for Neuroimaging, and ${ }^{2}$ Institute of Neurology, UCL, London WC1N 3BG, United Kingdom, ${ }^{3}$ Advanced Telecommunications Research \\ Institute International (ATR), Kyoto 619-0288, Japan, and ${ }^{4}$ Department of Engineering, University of Cambridge, Cambridge CB2 1PZ, United Kingdom
}

Predictions about sensory input exert a dominant effect on what we perceive, and this is particularly true for the experience of pain. However, it remains unclear what component of prediction, from an information-theoretic perspective, controls this effect. We used a vicarious pain observation paradigm to study how the underlying statistics of predictive information modulate experience. Subjects observed judgments that a group of people made to a painful thermal stimulus, before receiving the same stimulus themselves. We show that the mean observed rating exerted a strong assimilative effect on subjective pain. In addition, we show that observed uncertainty had a specific and potent hyperalgesic effect. Using computational functional magnetic resonance imaging, we found that this effect correlated with activity in the periaqueductal gray. Our results provide evidence for a novel form of cognitive hyperalgesia relating to perceptual uncertainty, induced here by vicarious observation, with control mediated by the brainstem pain modulatory system.

\section{Introduction}

A striking characteristic of human pain is an exquisite sensitivity to modulation by a range of endogenous and exogenous factors. One of the clearest examples is a sensitivity to predictive (anticipatory) information, with a rich literature describing conditions under which predictability modulates pain (Fields, 1999; Keltner et al., 2006; Kong et al., 2008; Atlas et al., 2010; Tracey, 2010). In studies of placebo analgesia, predictive information in the form of explicit expectancy, Pavlovian cues, and vicarious observation strongly influence pain experience (Voudouris et al., 1990; Montgomery and Kirsch, 1997; Colloca and Benedetti, 2009; Wager et al., 2011). However, what is not known is the precise nature of the predictive information that drives modulation of pain: is it the mean intensity of a prediction, its certainty/uncertainty, or the mere presence of a prediction itself? This is particularly important for understanding the endogenous pain modulatory system, and clinical attempts to harness it to treat pain.

There are three broad accounts of how predictability modulates pain. The first stems from theories of placebo analgesia, and

Received Oct. 25, 2012; revised Jan. 25, 2013; accepted Feb. 14, 2013.

Author contributions:W.Y., B.S., M.K., and R.J.D. designed research;W.Y. and B.S. performed research;W.Y. and B.S. contributed unpublished reagents/analytic tools; W.Y. analyzed data; W.Y., B.S., M.K., and R.J.D. wrote the paper.

This work was supported by the Wellcome Trust (R. Dolan Program Grant No. 078865/Z/05/Z). The Wellcome Trust Centre for Neuroimaging is supported by core funding from the Wellcome Trust (091593/Z/10/Z). A part of the research was supported by a contract with the Ministry of Internal Affairs and Communications entitled, "Novel and Innovative R\&D Making Use of Brain Structures." We thank 0. Josephs and N. Weiskopf for considerable help in optimizing thermal stimulation in the fMRI scanner.

The authors declare no competing financial interests.

Correspondence should be addressed to Dr. Wako Yoshida, Department of Computational Brain Imaging, Advanced Telecommunications Research Institute International, 2-2-2 Hikaridai Seika-cho, Sorakugun, Kyoto 6190288, Japan. E-mail: yoshida@atr.jp.

DOI:10.1523/JNEUROSCI.4984-12.2013

Copyright $\odot 2013$ the authors $\quad 0270-6474 / 13 / 335638-09 \$ 15.00 / 0$ relates to evidence suggesting that induction of reward (putatively dopaminergic) mechanisms, for example during relief prediction, exert an opponent inhibitory influence on pain (de la Fuente-Fernández et al., 2004; Lidstone et al., 2005; Fields, 2006; Scott et al., 2007; Enck et al., 2008; Leknes and Tracey, 2008; Zubieta and Stohler, 2009). This appeals to a reward-learning framework, and implicates assimilation of pain with its prediction through computations of the mean of a prediction (i.e., the "expected value").

The second class of explanation are perceptual theories (Brown et al., 2008; Morton et al., 2010; Critchley and Seth, 2012; Seymour and Dolan, 2012), which draw on parallels with expectancy effects seen in other sensory modalities. Accordingly, perception is viewed as an inference about the underlying cause of a sensory event: prediction is viewed as a perceptual prior, integrated with afferent input to generate subjective experience (Yuille and Kersten, 2006; Friston, 2010). These typically Bayesian theories rely both on the mean and uncertainty of the prediction, with uncertainty determining the extent to which the mean influences one's ultimate percept, such that more certain predictions exert a more powerful influence on perception than uncertain predictions.

The third class are psychological theories focusing predominantly on the role of uncertainty (Mineka and Hendersen, 1985), with the hypothesis that uncertainty itself may be inherently aversive, with pain reduced when more accurate predictions are made. This is supported by observations that giving people more accurate information about forthcoming pain can reduce reported aversiveness (Johnson, 1973; Johnson and Leventhal, 1974), as well as the consistent preference animals display for signaled over unsignaled painful shocks in laboratory experiments (Badia et al., 1979; Imada and Nageishi, 1982).

To test these differing accounts, we designed an experiment to independently manipulate both the mean and uncertainty of pain prediction. We adopted a vicarious observation paradigm, 
A

In the scanner

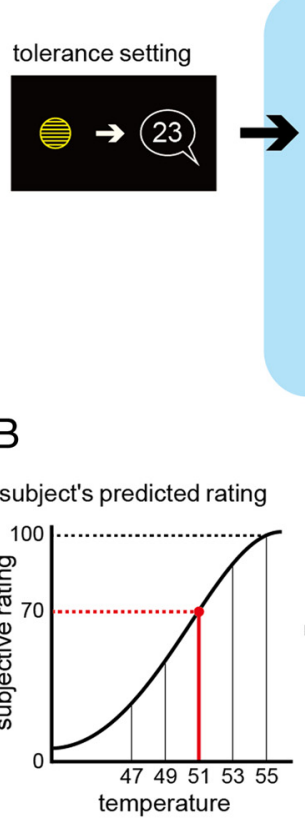
pre-experimental rating

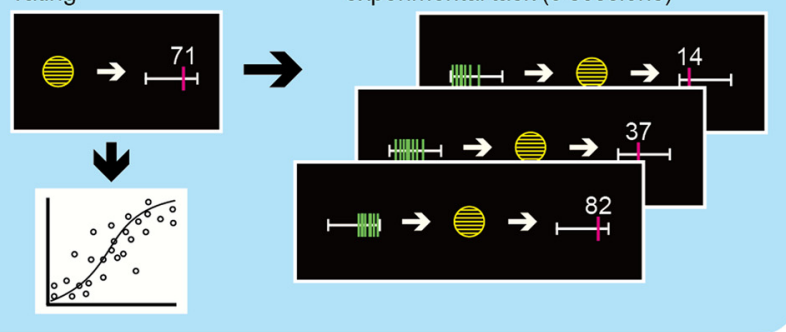

\section{B}
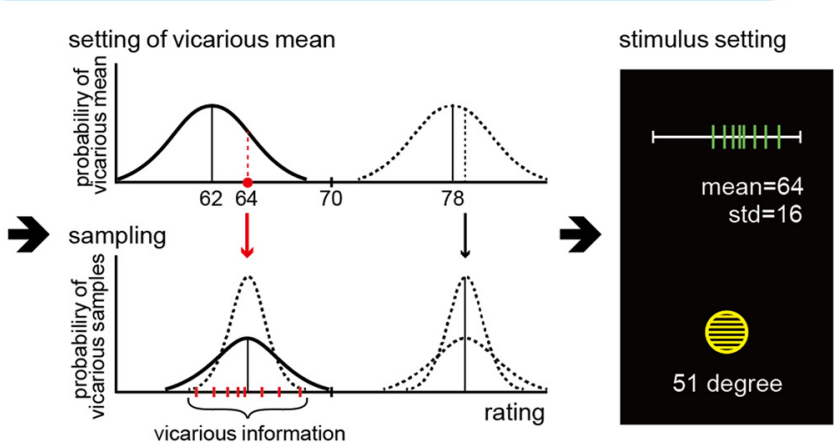

C

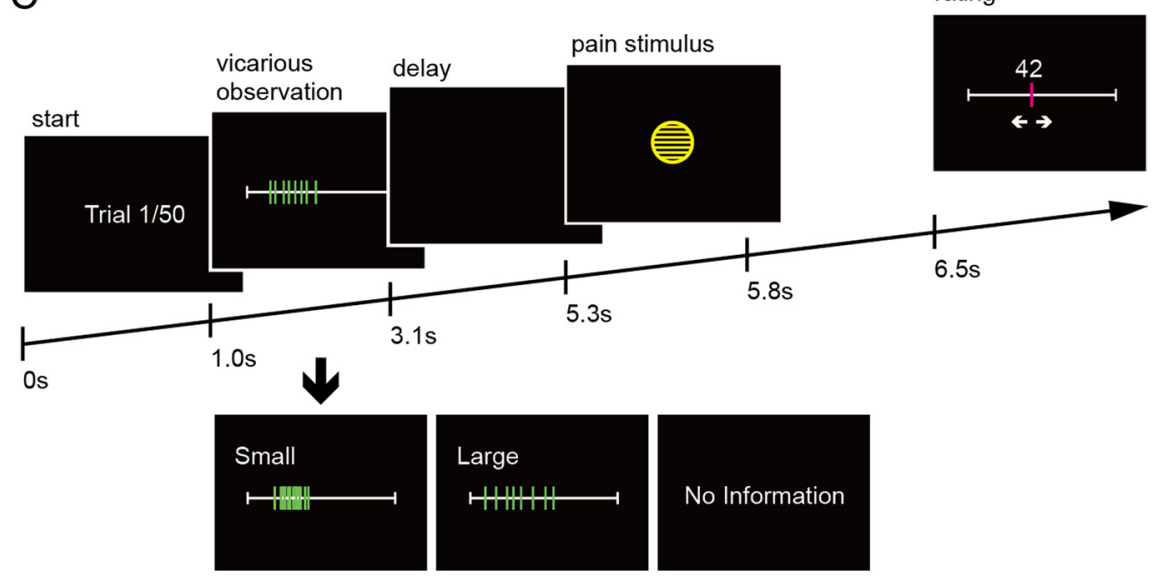

Figure 1. Experimental design. $\boldsymbol{A}$, The sequence of events was as follows. First, we performed a simple ramped pain tolerance procedure outside the scanner, to determine the upper limit of temperature to be used subsequently. Next, within the scanner, we performed a pre-experimental stimulus rating procedure using a random sequence of temperatures, with no vicarious information. We estimated the subject's stimulus (temperature)-response (pain rating) function by statistical fitting from rating data in the pre-experimental task (as shown schematically). Finally, we performed three experimental sessions, with vicarious information preceding the majority of pain stimuli. $\boldsymbol{B}$, This example illustrates how the vicarious information was generated. The exemplar trial is with an intermediate intensity stimulus - 51 degrees. Because we have estimated the temperature-pain rating function (as in $A$ ), we can predict that the subject would rate this temperature as $70 / 100$ on the pain scale, if it was presented with no vicarious information. On this trial, we decide to give vicarious information that is below the subjects predicted rating, but with large uncertainty. On average (i.e., over all such trials) we want the mean of the vicarious information to be 8 VAS points below the subject, but the deviation on each trials is sampled from a Gaussian distribution to induce greater variability. In this example, we sampled a value of 6 points below the subject i.e., pain rating of $64 / 100$. This is the mean of the vicarious information. The SD for a high uncertainty trial is pre-set to be 16 points. These statistics are used to sample eight fictitious people, shown as the green bars in the far right of the panel. The dotted lines show in the middle panel show putative distributions for low uncertainty vicarious information, as well as for high and low uncertainty ratings above the subjects rating. $C$, Trial structure. At the beginning of each trial, subjects viewed a pain ratings bar with eight marks corresponding to the ratings of eight fictitious people (we show both a high and low uncertainty example here). After $2.1 \mathrm{~s}$, the bar disappeared, and after a further $2.2 \mathrm{~s}$, subjects experience a short-lasting heat stimulus via the thermode. They then rated their own intensity judgment on the ratings bar, before proceeding to the next trial. Occasionally trials with no vicarious information were provided, to update the estimated stimulus-response function.

\section{Materials and Methods}

The experiment was inspired by a recent demonstration that witnessing judgments of other people's pain experience acts as an efficient mediator of placebo expectations (Colloca and Benedetti, 2009). This has the attractive property that it allows precise and orthogonal manipulation of the statistics of a prediction by allowing observation of judgments of pain derived from a vicarious group of other people. Significant concordance in perceived judgments of others permits accurate, more certain predictions, whereas widely varying judgments allow only uncertain predictions.

The overall basic structure of the experiment is as follows: first we assessed the pain threshold and tolerance in each experimental subject, and determined a detailed stimulus-response function relating temperature to the rated magnitude of pain, using a random sequence of thermal stimuli in the absence of any vicarious information. This allowed us to predict the most likely pain rating subjects would be expected to give to any particular temperature, based on which we could then provide vicarious information that was either above or below the subjects nonmanipulated "default" rating. Accordingly, in three experimental sessions, subjects observed a predetermined distribution of eight fictitious group ratings of a thermal stimulus selected to be either above or below their own predicted judgment, before receiving the stimulus. We used functional magnetic resonance imaging (fMRI), to identify associated brain responses to isolate, and anatomically dissociate, the neural representation of the different components of prediction. Figure 1 summarizes the experimental setup and an example trial illustrating how the vicarious information was generated. Figure $1 A$ shows the sequence of procedures for the whole task: first tolerance determination (outside the scanner), followed by determination of the psychophysical stimulus-response (temperature-pain rating) function, and finally the three experimental sessions, and an example of how the stimulus response function is generated from individual responses during the pre-experimental procedure; Figure $1 B$ shows the procedure used to determine the vicarious information, illustrated with an example; and Figure $1 C$ shows the sequence of events during a trial in the experimental sessions.

\section{Subjects}

Seventeen healthy subjects ( 9 females) participated in the experiment. All subjects had normal or corrected vision, were screened for a history of psychiatric or neurological problems, and were free of pain or pain medication. All subjects gave informed consent before the experiment and the study was approved by the Joint Ethics committee of the National Hospital for Neurology and Neurosurgery (UCLH NHS Trust) and the Institute of Neurology, UCL. in which people observed the pain ratings of a group of eight people before receiving the same pain stimulus themselves. By manipulating the mean and variance of the observed group, we were able to competitively test the above hypotheses.

\section{Stimuli, design, and pre-experimental test}

We used a contact heat-evoked potential stimulator (CHEPS; Medoc) to produce the ultra-brief noxious thermal stimuli. The thermode is composed of $570 \mathrm{~mm}^{2}$ heating thermofoil and permits subsecond heating at 
a rate of $70^{\circ} \mathrm{C} / \mathrm{s}$ up to $55^{\circ} \mathrm{C}$, followed by rapid cooling at a rate of $40^{\circ} \mathrm{C} / \mathrm{s}$ to baseline temperature of $30^{\circ} \mathrm{C}$. The average time from onset to peak temperature was $200-250 \mathrm{~ms}$ depending on the peak temperature. The thermode was attached to the lateral aspect of the left ankle using a Velcro strap. The experimental procedure commenced with a tolerance setting procedure, which was designed to familiarize the subjects with the thermal stimulation, and determine the maximum temperature that they could tolerate. In this procedure, they rated the intensity of pain after each of an ascending sequence of phasic thermal stimuli, with a minimum interstimulus interval of $10 \mathrm{~s}$. The phasic pain stimuli started from a low temperature, $37^{\circ} \mathrm{C}$, and slowly increased in steps of $1^{\circ} \mathrm{C}$ until the subjects indicated that they had reached their highest tolerated pain, or the maximum deliverable temperature of $55^{\circ} \mathrm{C}(16$ of 17 subjects).

Subjects were instructed to rate the intensity of felt pain. There are two important considerations here. The first is that the intensity of pain (considered a sensory-discriminative feature) is a slightly different construct than the aversiveness (unpleasantness/affective magnitude) of pain. This distinction is theoretically robust, with intensity reflecting a judgment about the magnitude of a pain-inducing stimulus, and aversiveness reflecting the behavioral and motivational significance of a stimulus. It is also experimentally robust, because behavioral, pharmacological and lesion studies can induce dissociations between each (Price, 2000). The second point is that there has been a long and divided debate about the best way to obtain ratings using a scale (Price et al., 1983). Points of debate have included whether and how to use anchoring labels, and whether to instruct people in the distinction between intensity and aversiveness, something which may not be immediately apparent to most subjects. Here, we elected to use $0-100$, with the following anchor labels: 0 is no heat at all, 30 just painful heat, and 100 is the worst imaginable heat pain.

After the initial tolerance setting procedure, and in the scanner, subjects then proceeded to a pre-experimental stimulus-rating procedure, in which they rated a sequence of heat stimuli as a location of a cursor (on the $0-100$ visual scale) on a computer display. The cursor was moved left or right by two keys on the keyboard, from a randomized starting position, and the response was confirmed by pressing a key. Subjects rated a sequence of 52 thermal stimuli in randomized order (with no vicarious information), allowing us to estimate a simple temperature-rating response function (see below). The reason for doing the pre-experimental stimulus-rating procedure in the scanner was to ensure that the ratings were garnered in exactly the same environment as the three experimental sessions, to allow us to carry over the results from the pre-experimental session to the experimental sessions. This is necessary because these sorts of environmental contextual factors might conceivably influence ratings. The three experimental sessions also included scattered simple stimulus-response rating trials within it, identical to those that occur in the preexperimental session, to allow us to constantly update each subject's stimulus-rating response function.

Subjects then performed three experimental sessions. Each comprised 50 trials in which pain was preceded by vicarious information (Fig. 1). The temperatures used comprised a random sequence with five levels of temperature up to and including their individually set maximum tolerance level. Between sessions, the thermode was moved a small amount to an adjacent area of skin, to reduce the possibility of habituation or sensitization. Using a two-way ANOVA, we found that there was no significant main effect of session number $\left(F_{(2,34)}=0.1, p=0.904\right)$, or interaction of session number and temperature $\left(F_{(2,34)}=0.11, p=\right.$ 0.999). Neither was there any evidence of habituation in the preexperimental task (without vicarious information): by looking at ratings to repetitions of the same temperature during the pre-experimental task, a two-way ANOVA revealed no significant effect of trial (repetition) number $\left(F_{(2,360)}=0.18, p=0.833\right)$, or interaction of trial number and temperature $\left(F_{(2,360)}=0.21, p=0.999\right)$. There was also no difference in mean pain ratings during the pre-experimental trials and the trials without vicarious information during the experimental task $\left(F_{(1,117)}=0.92\right.$, $p=0.339$ ). Because sensitization and habituation effects can occur at shorter timescales, the order of temperature was fully randomized, which orthogonalizes the influence (i.e., noise) induced by such processes.

\section{Experimental task and behavioral screening}

In the experimental task itself, subjects rated the intensity of brief thermal stimuli based on their own experience, following informed vicarious observation of the ratings of others', of the same stimulus (Fig. 1). On each trial in the experimental session, the subject was given the vicarious observation on a computer monitor, followed by the thermal stimulus, and then required to rate it on the computer. The vicarious information was shown as eight bars on the rating scale, with each bar corresponding to one individual.

The vicarious information was therefore under experimental control, but within the (diverse) limits of true ratings in our subjects from our previous experiments. That is, the ratings were not generated by an actual, defined vicarious group of eight people, but rather were specified "arbitrarily" by us. Subjects were told that the ratings were the true ratings of people who had previous come to our lab. Because we have studied thermal and pain sensation in a large number of people previously, and because variation in responses is widespread, this statement is entirely true, and hence no deception is involved.

Because the experimental manipulation concerns the mean and variance of vicariously observed ratings, these ratings need to be selected appropriately. More specifically, the vicarious information needs to be either higher or lower than the rating that the subject would be expected to give in the absence of any other information. Thus, we need to estimate the subjects own temperature-rating response function throughout the course of the experiment, to know how to select the vicarious information. At the beginning of the experiment, this is based on the preexperimental session, in which subjects merely rate a random sequence of temperatures, as above. We statistically fit a sigmoid (Weibull) function to the ratings using a maximum likelihood procedure (in Matlab) (Fig. $1 A$ ). Weibull functions naturally describe physiological response functions, and the fitting procedure allows us to find the shape of the function that best describes the relationship between temperature $(x)$ and rating on an individual basis. This is defined by the three parameters (the shape, scale, and location parameters) in the general equation:

$$
H(x)=\alpha\left(1-2^{-(x / \lambda)^{\kappa}}\right) .
$$

The shape is typically sigmoid, but can also look more linear or exponential, depending on each subject's responses. That is, this function has a general form that can assume a range of shapes, including that of a power law as has previously been studied for thermal pain (Adair et al., 1968).

This function is in fact the "absolute" (null) model, described below, which presumes that subjects ignore vicarious information throughout the task. After each experimental session, we reestimate the temperaturerating response function based on the ratings in the session, which includes several trials in which no vicarious information was given. As we used various ranges of means and variances for the group ratings, we assume that the subject's rating bias induced by vicarious information is roughly orthogonalized, and does not induce any systematic bias in this response function. This assumption is supported by the fact that the temperature-rating functions were not significantly different between three experimental sessions, and between the pre-experimental task without vicarious information and the experimental task.

Given this absolute temperature-rating function, we then draw eight samples representing putative other subjects ratings (vicarious information) from a Gaussian distribution:

$$
N\left(H(x)+\theta, \sigma^{2}\right)
$$

where $H(x)$ is subject's predicted rating calculated individually from the temperature-rating function for the specific temperature to be used on that trial. The difference between the subjects predicted rating and the set vicarious mean, $\theta$, was set at positive $(\theta=8)$ or negative $(\theta=-8)$. The variance of vicarious information was set at one of two levels, small and large, with a variance of 36 (i.e., SD of 6) and 256 (SD of 16), respectively (Fig. $1 B$ ). Immediately after the display of vicarious information, available for $2.1 \mathrm{~s}$, the thermal stimulus was delivered and the subject rated it by moving the cursor on the scale of $0-100$ from the randomly located 
initial position. Subjects performed three sessions in total, including the trials without vicarious information.

The temperature-rating response function provides us not only with a best fitting response curve, but also with an estimate of how consistent subjects are in their ratings. This latter metric is a useful indicator of whether the task has failed for any particular methodological reason in any individual subject. We identified three outlier subjects whose ratings were highly inconsistent, and the reason appeared likely to be their failure to engage seriously with the task. Hence, these subjects were excluded from further analysis. We excluded one further subject who did not rate $>30$ at all (i.e., not painful) for any stimuli.

\section{Data analysis}

\section{Categorical analysis}

The initial behavioral analysis considers categorically the different trials types according to whether the vicarious information was above or below the subjects predicted rating from the absolute temperature-rating response function, and according to whether the vicarious information was of high or low variance, using a frequentist approach. To allow comparison between subjects, we normalized the deviation within subjects, and these deviations were then used as summary statistics taken to a second level random-effects analysis.

\section{Computational modeling}

We then analyzed the data using a structured (computational) model of how perceptual judgments are based on social evaluation in the task, based on the different accounts, as outlined in the introduction. This computational formalization allows us to individually fit and parameterize distinct effects of mean and uncertainty, and test the overall goodness of fit of each model. In doing so, we formally compare them using Bayesian model comparison. Including the null hypothesis, we introduce the four probabilistic generative models of subject's pain rating below.

Absolute model. The first model represents the null hypothesis, and assumes that there is no effect of the vicariously observed information on subjects' ratings. We term this the absolute model, which posits a stable, standard sigmoid response function (Weibull function, $H(x)$, as described above) that maps a given nociceptive input (temperature stimulus) to a subjects rating. As mentioned above, the sigmoid function is a standard physiological response function, and the parameters, which we fit on an individual level, determine its shape.

$$
N\left(H(x), \sigma_{\mathrm{abs}}^{2}\right) .
$$

Mean-only model. In the second model, the subjects' rating incorporates both the ascending nociceptive input, and the mean of the vicarious information. The nociceptive input is assumed to be a sigmoid function as above, which is linearly combined with the mean of the ratings of others. Thus, the model assumes an isolated effect of the mean of the prediction, but does not incorporate uncertainty. This linear assimilation process is a $\delta$-rule updating procedure (which is equivalent to a RescorlaWagner, or temporal-difference update rule), in which the extent to which the nociceptive input is biased toward the vicariously observed mean is determined by a learning rate: $\alpha$.

$$
N\left(H(x)+\alpha \delta, \sigma_{\text {mean }}^{2}\right) .
$$

Bayesian model. The third model incorporates both the mean and uncertainty in a statistically optimal way, according to Bayes rule. Thus, rather than using a single value for the nociceptive input and vicarious information, it uses their estimated distributions (i.e., the mean and uncertainty, assuming they are each Gaussian). Thus, the nociceptive input becomes the likelihood distribution, which incorporates the subject's own uncertainty about their rating (given by the variability in their ratings), and the prior distribution is determined directly from the vicarious information (calculated numerically from the eight responses on each trial). The subjects' rating is therefore calculated as the mean of posterior distribution, estimated using Bayes rule (i.e., proportional to the product of the likelihood and prior distributions). Thus, the Bayesian model is effectively an enhanced version of the meanonly model, in which the degree of concordance (i.e., vicarious certainty) in the social evaluation determines how much weight the subject places on it. A smaller variance in others judgments thus yields a greater influence on a subjects rating.

$$
N\left(\mu_{\text {bayes }}, \sigma_{\text {bayes }}^{2}\right)=N\left(H(x), \sigma_{\text {lik }}^{2}\right) N\left(H(x)+\theta, \sigma^{2}\right) .
$$

Uncertainty-hyperalgesia model. The fourth model extends the Bayesian model, by parameterizing an additional, independent effect of the (posterior) uncertainty on ratings. In the Bayesian model, uncertainty merely gates the influence of the prior mean, but itself does not increase (or decrease) pain judgments. In the uncertainty-hyperalgesia model, the Bayesian posterior distribution is calculated exactly as previously, but an uncertainty bias is incorporated (of size). The bias hence can increase pain ratings when subjects are more uncertain, akin to a subjective perceptual "risk aversion."

$$
N\left(\mu_{\text {bayes }}+\beta \sigma_{\text {bayes }}^{2}, \sigma_{\text {bayes }}^{2}\right) .
$$

For each of these models, we estimated both the goodness of fit, and the model parameters from the subjects' individual trial-by-trial ratings, using a maximum likelihood technique. We then compared each model using a Bayesian model selection procedure incorporating the Bayesian information criteria (BIC), which is the standard way to compare models taking into account their different levels of complexity (i.e., numbers of free parameters).

As detailed in Results, the winning model is the uncertaintyhyperalgesia model. Hence, the estimated model parameters (likelihood variance and $\beta$ ) were subsequently used to generate subject-by-subject, trial-by-trial regressors for neuroimaging analysis.

\section{fMRI experiment and analysis}

A 3T Trio whole-body scanner with standard transmit-receive head coil was used to acquire functional data with a single-shot gradient echo isotropic high-resolution echo-planar imaging (EPI) sequence (matrix size: $128 \times 128$; Fov: $192 \times 192 \mathrm{~mm}^{2}$; in-plane resolution: $1.5 \times 1.5$ $\mathrm{mm}^{2} ; 40$ slices with interleaved acquisition; slice thickness: $1.5 \mathrm{~mm}$ with no gap between slices; TE: $30 \mathrm{~ms}$; asymmetric echo shifted forward by 26 phase-encoding (PE) lines; acquisition time per slice: $68 \mathrm{~ms}$; TR: 2720 $\mathrm{ms})$. The number of volumes acquired depended on the behavior of the subject. A high-resolution T1-weighted structural scan was obtained for each subject ( $1 \mathrm{~mm}$ isotropic resolution 3D MDEFT) and coregistered to the subject's mean EPI image. The mean of all individual structural images permitted the anatomical localization of the functional activations at the group level.

Statistical parametric mapping (SPM8; Wellcome Trust Centre for Neuroimaging, UCL) was used to preprocess all fMRI data, which included spatial realignment, normalization and smoothing. To control for motion, all functional volumes were realigned to the mean volume. Images were spatially normalized to standard space Montreal Neurological Institute $(\mathrm{MNI})$ template with a resample voxel size of $2 \times 2 \times 2 \mathrm{~mm}$ and smoothed using a Gaussian kernel with an isotropic full width at half maximum (FWHM) of $8 \mathrm{~mm}$. In addition, high-pass temporal filtering with a cutoff of $128 \mathrm{~s}$ was applied to remove low-frequency drifts in signal and global changes were removed by proportional scaling.

Following preprocessing, statistical analysis was conducted using the general linear model. Each trial was modeled with impulse stimulus functions at two time points: the time of pain prediction as determined by the presentation of the vicariously observed information, and the time of actual delivery of pain. For the pain prediction event, we used the mean and variance of vicarious information as the parametric functions of prediction (prior) of pain intensity and uncertainty. For the parametric functions at the time of pain delivery, we simulated the uncertaintyhyperalgesia model using the actual stimulus and response sequences to generate the subject's posterior evaluation of pain intensity (mean) and uncertainty (variance). For completeness, we also compared responses on all trials with vicarious information (regardless of the information or pain level) with all the trials without vicarious information (regardless of pain level). We note here that this identified activity in right hippocampus $(x=30, y=-8, z=-12 ; Z=4.61)$. Because we had no specific a priori hypothesis about this activity, and it does not survive whole brain correction, we note here but do not discuss it further in Results. 
All stimulus functions were then convolved with the canonical hemodynamic response function and entered as orthogonalized regressors into a standard general linear convolution model of each subject's fMRI data using SPM, allowing independent assessment of the activations that correlated with each model's predictions. The six scan-to-scan motion parameters produced during realignment were included as additional regressors in the SPM analysis to account for residual effects of scan-to-scan motion. To enable inference at the group level, the parameter estimates for the two model-based parametric regressors from each subject were taken to a second level; random-effects group analysis using one-sample $t$ tests. Given the substantial intersubject variability in susceptibility to uncertainty-induced hyperalgesia, we adopted a covariate approach to model uncertainty. In effect, this weights the magnitude of each subject's uncertainty-related brain responses by the amount to which the subject showed a behavioral effect. Activity in such a contrast can be thought of as supporting a modulatory role relating the contrast (the parametric correlation with uncertainty) with which the covariate is applied. Note also therefore that although the brain responses we report in the second level (random effects) analysis necessarily incorporate intersubject variability, they do not (statistically) necessarily explain it.

\section{Regions of interest and correction for multiple comparisons}

We report brain responses that are corrected for multiple comparisons in a priori regions of interest based on previous data, using a familywise error (FWE) correction of $p<0.05$. ROIs were $8 \mathrm{~mm}$ spherical volumes based on coordinates from previous studies. For the endogenous modulation of pain according to uncertainty, we specified the periaqueductal gray (PAG) anatomically ( $x=0, y=-8, z=-12 ; p=0.036$ ), as this is the single region most consistently associated with the modulation of pain. For regions associated with the anticipatory processing of pain, and the mean effect of pain, we specified the bilateral anterior insula (left: $x=$ $-44, y=16, z=4 ; p=0.013$; right: $x=44, y=16, z=4 ; p=0.025)$ (Ploghaus et al., 1999), anterior cingulate cortex $(x=0, y=24, z=32$; $p=0.04)$ (Keltner et al., 2006), and sensory thalamus (left: $x=-10, y=$ $-18, z=12 ; p=0.01$; right: $x=10, y=-18, z=12 ; p=0.03$ ) (Keltner et al., 2006), because these areas are consistently implicated in expectation/prediction related pain processing. Beyond our ROIs, we accept a significance threshold of $p<0.05$ whole brain corrected.

\section{Results}

Figure $2 A$ shows the patterns of modulation predicted by a set of different theoretical models. The placebo model simply predicts that the subject's rating is biased toward the mean of vicarious ratings, and does not take into account the variance of the ratings. However, the Bayesian model incorporates the variance, such that a smaller variance in the vicarious rating yields a stronger influence on the subject's own rating. Finally, in the uncertainty hyperalgesia model, high variance of vicarious ratings increases pain regardless of the mean. Figure $2 B$ shows the actual data, which on inspection is most similar to the uncertaintyhyperalgesia model. When the vicarious information is more certain, and lower, than the subjects own unmodulated "default" rating, subjects were biased in their ratings toward the vicarious group. However, when this vicarious group displayed greater uncertainty, this bias was largely abolished. When the vicarious information was high and certain, subjects showed little increase in their ratings. However, when the fictitious vicarious rating dis- played greater uncertainty, this had the effect of substantially increasing pain.

Thus, it can be seen that on the whole (i.e., collapsing across different levels of uncertainty), subjects were biased toward the mean of the vicarious group - consistent with previous studies of vicarious placebo and nocebo responses (Colloca and Benedetti, 2009). However, this effect is clearly dependent on the associated uncertainty, where in both cases (when the mean was above and below the subjects expected ratings) uncertainty has the effect of increasing pain.

To formalize the statistical difference between the models, we calculated the log likelihood of subjects' ratings given four simple computational formalizations of the models. Specifically, these comprised: (1) a stable response function with no influence of vicarious information (null hypothesis, absolute model); (2) an isolated effect of the mean of vicarious information (mean-only model); (3) a perceptual inference model using Bayesian integration of prior expectation and stimulus likelihood (Bayesian model); and (4) a Bayesian model with an additional hyperalgesic effect of uncertainty (uncertainty-hyperalgesia model). Using Bayesian model selection, it can be seen that the uncertaintyhyperalgesia provides by far the best explanation of the data than the absolute, mean-only, or simple Bayesian models (Fig. 2C).

Next we studied brain activity associated both with prediction and receipt of the pain stimulus, to identify the brain areas correlated with the mean and uncertainty. We adopted a computational fMRI-based approach (O'Doherty et al., 2007; Friston and Dolan, 2010), which probes activity specifically correlated with the mean and uncertainty on a trial-by-trial basis. First, we looked at activity time-locked to the observation of others judgments and examined the parametric correlation with the mean of subjects' judgments. We observed brain responses in ventromedial and ventroposterolateral thalamus, dorsomedial prefrontal cortex, and bilateral anterior insula cortex (Fig. 3A). This indicates that vicarious observation alone induces significant activity in pain-related thalamo-cortical regions, and this correlated with the anticipated intensity of pain.

We then looked at brain responses correlated with the anticipatory uncertainty, covaried with individual susceptibility to uncertainty-induced hyperalgesia (parameter $\beta$ in the uncertainty-hyperalgesia model) estimated from each sub- 


\section{A Anticipatory intensity of pain}

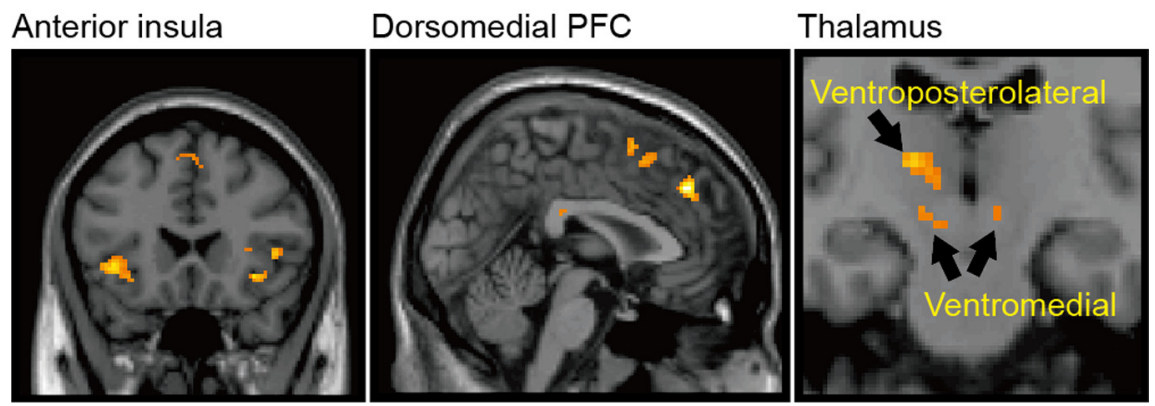

B Anticipatory uncertainty
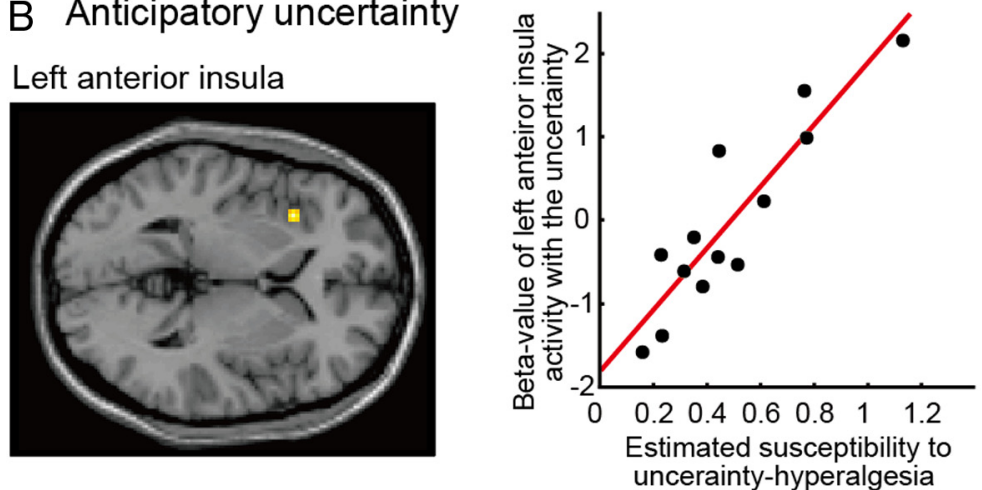

Figure 3. $A$, Brain activations correlated with the anticipated intensity of pain, including bilateral anterior insula cortex $(x=$ $-40, y=18, z=-2 ; x=54, y=18, z=6)$, dorsomedial prefrontal cortex $(x=2, y=38, z=38)$, and thalamus (ventromedial: $x=-10, y=-16, z=-8 ; x=8, y=-16, z=-6$ and ventroposterolateral: $x=-14, y=-18, z=$ 6). $\boldsymbol{B}$, The left anterior insula $(x=-34, y=20, z=2)$ activity correlated with responses to the anticipatory uncertainty of pain, when the response is covaried with the intensity of hyperalgesic effect. It can be seen that this effect, on the $x$-axis, varies significantly across subjects. Activity also extends below zero, indicating that subjects who were less susceptible to uncertaintyhyperalgesia showed relative deactivation in anterior insula.

\section{Inferred intensity of given pain}

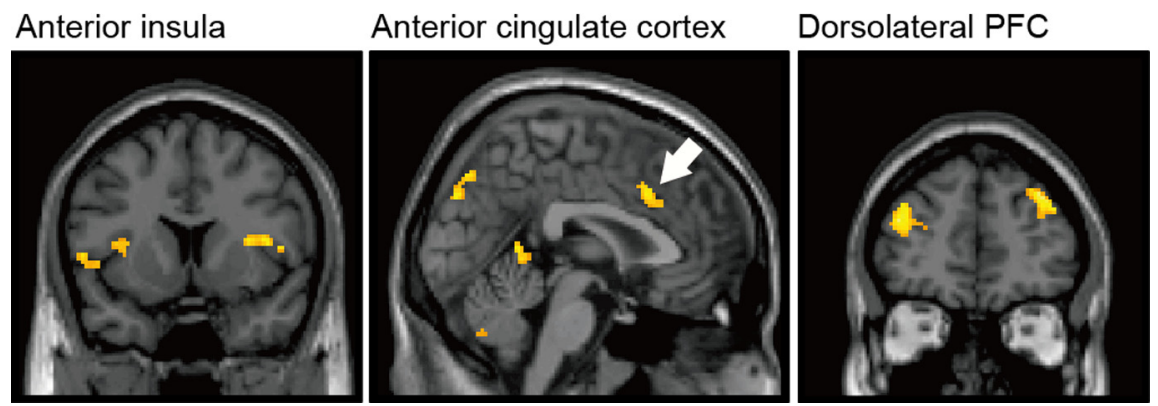

Figure 4. Brain activations correlated with pain modulated by the mean expectation, without incorporating the hyperalgesic effect of uncertainty, including bilateral anterior insula $(x=-54, y=8, z=6 ; x=50, y=10, z=8)$, anterior cingulate cortex $(x=4, y=20, z=34)$, and bilateral dorsolateral prefrontal cortex $(x=36, y=44, z=34 ; x=-36, y=48, z=24)$.

ject's behavioral data. This revealed responses in left (ipsilateral) anterior insula (Fig. $3 B$ ). That is, activity in this region showed a greater neural response to anticipatory uncertainty in subjects who showed a greater behavioral uncertainty-hyperalgesic response.

Next, we examined brain responses time-locked to the actual receipt of the painful stimulus. First, we looked at responses correlated with the inferred mean of pain; that is, activity correlated with pain modulated by the mean expectation, without incorporating the hyperalgesic effect of uncertainty. This identified re- sponses in bilateral anterior insula and anterior cingulate cortex, as well as bilateral dorsolateral prefrontal cortex (Fig. 4).

Last, we examined brain responses related to uncertainty at the time of pain receipt, using subject susceptibility to hyperalgesia as a covariate, as before. This analysis identified a response in the brainstem, in a region incorporating the periaqueductal gray (Fig. 5). To check the anatomical location of the activity, we confirmed all three axes of our peak activity voxel $(x=8, y=-24, z=-12)$, and also $75 \%$ of significantly activated voxels (18/24 voxels, $p<0.05)$, are located within a SD of the mean of the PAG activation peak calculated as the metaanalysis of previous studies $(x=4 \pm 3$, $y=-29 \pm 5, z=-12 \pm 7$ ) (Linnman et al., 2012). The distribution of responses is shown in the right-hand panel: subjects with greater responses to uncertainty showed greater uncertainty-hyperalgesia at a behavioral level, whereas subjects who showed low or negative responses to uncertainty (i.e., positive responses to certainty) showed less uncertainty-induced hyperalgesia behaviorally.

\section{Discussion}

These results illustrate that uncertainty regarding pain intensity during anticipatory processing, induced by vicarious observation of a social group, induces potent hyperalgesia in humans. In particular, we show that susceptibility to this effect is correlated with brain responses to uncertainty in the periaqueductal gray. These results characterize a novel and specific mechanism of hyperalgesia in humans, and illustrate its neurophysiological basis in pain perception in humans.

Our results add to a body of literature concerning the importance of uncertainty in pain and aversive processing (Jones et al., 1966; Badia et al., 1979; Imada and Nageishi, 1982; Mineka and Hendersen, 1985). Many of these studies, performed in animals, compared predictability in terms of whether a painful shock is predictable in time, and explanations of this preference for predictability emphasize the adaptive value of timed response preparation, and the positive (rewarding) value accruing from implied periods of safety (Seligman and Binik, 1977). However, few studies have considered the statistical uncertainty about pain magnitude itself (although preference for predictive cues informing rats of the duration of shock has been reported) (D'Amato and Safarjan, 1979). Furthermore, it has remained unclear whether preference for predictability (through choice) necessarily implies that pain is perceived as less intense, and indeed some animal studies have even suggested the opposite (Miller et al., 1983). Similarly, in humans, previous studies have 
not dissociated the effect of uncertainty on pain perception from the contextual effects of fear and anxiety (Johnson and Leventhal, 1974; Ploghaus et al., 2001), the provision of information (which is inherently reinforcing) (Feather, 1967), and the mean value of a prediction (Ploghaus et al., 2003), such that is has remained unclear whether such an effect should exist at all (Leventhal et al., 1979). In our study, given the control afforded by selective manipulation of the statistics inherent in vicarious observation, we show that predictive uncertainty over pain intensity selectively increases its subjective perception.

The identification of brainstem activity, in a region consistent with the PAG, time-locked the receipt of pain and predicting uncertainty-induced hyperalgesia across subjects points to a new role for this structure in pain modulation. The PAG is intimately linked with behaviors associated with threat, fear and pain, and (in animals) has been shown to include anatomical regions subserving distinct functional roles relating to processing different aspects of pain and threat (Keay and Bandler, 2002; Lumb, 2004), all associated with nociceptive modulation (Reynolds, 1969; Basbaum and Fields, 1984; Morgan et al., 1991; Behbehani, 1995). Our data provide in vivo human evidence that the PAG plays a role in the specific expression of uncertaintyinduced hyperalgesia. This may be closely related to other modulatory functions of the PAG, namely that related to mediation of the analgesic effect of instrumental controllability (Lumb, 2004; Salomons et al., 2007). Controllability and predictability are distinct but intricately related aspects of behavior (Overmier, 1983; Mineka and Hendersen, 1985), and our data suggest they may share a common pathway in pain modulation.

The PAG is well known for its complex role in pain modulation, mediating both inhibition and facilitation (Vanegas and Schaible, 2004) of pain. It has been argued that the balance between these opposing influences determines the "tone" of descending pain modulation in different physiological and pathological states (Bee and Dickenson, 2007). The nature of the modulation seen here may reflect this tonic opponency: subjects in whom we found strong behavioral evidence of hyperalgesia in the face of uncertainty, BOLD responses in the PAG increased in response to (i.e., is positively correlated with) uncertainty. However, in subjects who are relatively insensitive to developing hyperalgesia with uncertainty, BOLD responses correlated inversely with uncertainty (Fig. 5). This is analogous to saying that BOLD response increases in response to certainty. Importantly, the nature of the PAG response to uncertainty appears to determine the behavioral sensitivity to uncertainty, in keeping with a modulatory effect, as opposed to an invariant representation of uncertainty per se. However, note that the PAG is an important projection site of ascending pain pathways, and might also have a role in pain modulation distinct from that attributable to descending projections to the dorsal horn. Our current experiment cannot in itself determine precisely the mechanism of modulation, although future studies could exploit designs that permit directional connectivity analysis (such as dynamic causal modeling) between brainstem and cortical sites.

It was previously suggested that cholecystokinin (CCK) may mediate pronociceptive effects of anxiety and considerable evi- dence points to the role of CCK (in the PAG) in anxiety related hyperalgesia, nocebo hyperalgesia, and opponent modulation of placebo analgesia (Lovick, 2008). Thus, CCK is a strong candidate in mediating a neuromodulatory control of uncertaintyinduced hyperalgesia, which can link anxiety-induced (as a psychological account) and uncertainty-induced (as a computational/mechanistic account) aspects of pain. This hypothesis could be tested in future mechanistic studies that, in principle, could provide a lead for novel therapeutic approaches in pain relief.

The anterior insula has a well documented role in interoception and pain sensation (Craig et al., 2000; Craig, 2002). Here, we show that activity correlates both with distinct, orthogonal components of pain anticipatory processing: i.e., both the predicted mean of pain and its uncertainty, affirming its central role in the cortical processing of thermal pain. The nature of the representation of uncertainty is also likely to be modulatory, given that it derives from the same type of covariate regression as with the PAG. It is particularly noteworthy that many previous social neuroscience tasks involving observation of pain have interpreted anterior insula function in terms of other-regarding (empathic) responses (Singer et al., 2004), and much less in terms of information acquisition, as we show here, with which it often cooccurs. Such a representation of uncertainty may not be restricted to pain; however, as previous experiments in financial decision-making have shown a specific representation of uncertainty in anterior insula in a similar mean variance theoretic context, but in the context of choice rather than perception (Preuschoff et al., 2006).

The importance of uncertainty does not negate a strong role for the mean of a prediction, and the main effect of mean predicted pain that we show clearly illustrates a powerful effect of social assimilation. This supports mean-based accounts implied by many contemporary theories of placebo and nocebo effects (de la Fuente-Fernández et al., 2004; Lidstone et al., 2005; Fields, 2006; Scott et al., 2007; Enck et al., 2008; Leknes and Tracey, 2008; Zubieta and Stohler, 2009; Tracey, 2010). This is inherent in the computational formalization of the uncertainty-hyperalgesia model, which incorporates both uncertainty and mean influence on pain. However, the magnitude of the specific hyperalgesic effect of uncertainty makes it difficult to determine whether the underlying mean effect is linear (as in the mean-only model) or modulated by uncertainty (as in the Bayesian model). Either way, 
our data suggest a formal basis for understanding the dependency of placebo and nocebo responses on the certainty of information.

The involvement of extensive thalamo-cortical regions in anticipatory processing of pain provides further evidence of extensive dynamic connectivity along the entire neuroaxis in pain processing, in keeping with a notion that pain is a hierarchical, reciprocally connected system, as opposed to a unidirectional "feedforward" processing stream (Ploghaus et al., 1999; Sawamoto et al., 2000; Porro et al., 2002; Wager et al., 2004; Koyama et al., 2005; Keltner et al., 2006; Fairhurst et al., 2007; Eippert et al., 2009; Ploner et al., 2010). The involvement of dorsolateral prefrontal cortex also fits with previous suggestions that suggest this region has a modulatory role in mediating expectancy-related effects, including observation that localized transcranial magnetic stimulation abolishes placebo analgesic effects (Krummenacher et al., 2010; Borckardt et al., 2011). Understanding the individual roles of these areas is an important future challenge, because lesions of each can either cause (e.g., thalamic stroke) or alleviate (e.g., anterior cingulotomy) chronic pain.

Finally, our data provide evidence for how vicariously acquired information can shape the private experience of pain (Colloca and Benedetti, 2009). Socially communicated information is ubiquitous in humans (Tomasello, 1999) and especially important in the context of potential threat (White and Galef, 1998; Olsson and Phelps, 2007) and pain (Langford et al., 2006; Goubert et al., 2011; Hadjistavropoulos et al., 2011) across species. It is particularly interesting to note that humans use the statistical information from the group, as opposed to merely imitating or conforming to the responses of single or representative individual, which extends our understanding of the nature of vicarious information acquisition in humans (Morrison and Downing, 2007; Klucharev et al., 2009). Whether or not the effect of uncertainty on pain perception generalizes to other methods by which predictions are generated (e.g., verbal instructions or Pavlovian cues) is an interesting future question, and it may be the effect is specific to socially transmitted information. Either way, an enormous amount of adaptive human behavior uses vicariously acquired information. One example of this is in "doctor-patient interactions" (Benedetti, 2011): an intriguing implication is that the confidence displayed by health professionals may increase the therapeutic benefit of the placebo component of clinical interventions.

\section{References}

Adair ER, Stevens JC, Marks LE (1968) Thermally induced pain, the DOL scale, and the psychophysical power law. Am J Psychol 81:147-164. CrossRef Medline

Atlas LY, Bolger N, Lindquist MA, Wager TD (2010) Brain mediators of predictive cue effects on perceived pain. J Neurosci 30:12964-12977. CrossRef Medline

Badia P, Harsh J, Abbott B (1979) Choosing between predictable and unpredictable shock conditions: data and theory. Psychol Bull 86: 1107-1131. CrossRef

Basbaum AI, Fields HL (1984) Endogenous pain control systems: brainstem spinal pathways and endorphin circuitry. Annu Rev Neurosci 7:309-338. CrossRef Medline

Bee LA, Dickenson AH (2007) Rostral ventromedial medulla control of spinal sensory processing in normal and pathophysiological states. Neuroscience 147:786-793. CrossRef Medline

Behbehani MM (1995) Functional characteristics of the midbrain periaqueductal gray. Prog Neurobiol 46:575-605. CrossRef Medline

Benedetti F (2011) The patient's brain: the neuroscience behind the doctorpatient relationship. New York: Oxford UP.

Borckardt JJ, Reeves ST, Frohman H, Madan A, Jensen MP, Patterson D, Barth K, Smith AR, Gracely R, George MS (2011) Fast left prefrontal rTMS acutely suppresses analgesic effects of perceived controllability on the emotional component of pain experience. Pain 152:182-187. CrossRef Medline

Brown CA, Seymour B, Boyle Y, El-Deredy W, Jones AK (2008) Modulation of pain ratings by expectation and uncertainty: behavioral characteristics and anticipatory neural correlates. Pain 135:240-250. CrossRef Medline

Colloca L, Benedetti F (2009) Placebo analgesia induced by social observational learning. Pain 144:28-34. CrossRef Medline

Craig AD (2002) How do you feel? Interoception: the sense of the physiological condition of the body. Nat Rev Neurosci 3:655-666. CrossRef Medline

Craig AD, Chen K, Bandy D, Reiman EM (2000) Thermosensory activation of insular cortex. Nat Neurosci 3:184-190. CrossRef Medline

Critchley H, Seth A (2012) Will studies of macaque insula reveal the neural mechanisms of self-awareness? Neuron 74:423-426. CrossRef Medline

D'Amato MR, Safarjan WR (1979) Preference for information about shock duration in rats. Animal Learn Behav 7:89-94. CrossRef

de la Fuente-Fernández R, Schulzer M, Stoessl AJ (2004) Placebo mechanisms and reward circuitry: clues from Parkinson's disease. Biol Psychiatry 56:67-71. CrossRef Medline

Eippert F, Finsterbusch J, Bingel U, Büchel C (2009) Direct evidence for spinal cord involvement in placebo analgesia. Science 326:404. CrossRef Medline

Enck P, Benedetti F, Schedlowski M (2008) New insights into the placebo and nocebo responses. Neuron 59:195-206. CrossRef Medline

Fairhurst M, Wiech K, Dunckley P, Tracey I (2007) Anticipatory brainstem activity predicts neural processing of pain in humans. Pain 128:101-110. CrossRef Medline

Feather NT (1967) An expectancy-value model of information-seeking behavior. Psychol Rev 74:342-360. CrossRef Medline

Fields HL (2000) Pain modulation: expectation, opioid analgesia and virtual pain. Prog Brain Res 122:245-253. CrossRef Medline

Fields HL (2006) A motivation-decision model of pain: the role of opioids. In: Proceedings of the 11th World Congress on Pain (Flor H, Kalso E, Dostrovsky JO, eds), pp 449-459. Seattle: IASP.

Friston K (2010) The free-energy principle: a unified brain theory? Nat Rev Neurosci 11:127-138. CrossRef Medline

Friston KJ, Dolan RJ (2010) Computational and dynamic models in neuroimaging. Neuroimage 52:752-765. CrossRef Medline

Goubert L, Vlaeyen JW, Crombez G, Craig KD (2011) Learning about pain from others: an observational learning account. J Pain 12:167-174. CrossRef Medline

Hadjistavropoulos T, Craig KD, Duck S, Cano A, Goubert L, Jackson PL, Mogil JS, Rainville P, Sullivan MJ, de C Williams AC, Vervoort T, Fitzgerald TD (2011) A biopsychosocial formulation of pain communication. Psychol Bull 137:910-939. CrossRef Medline

Imada H, Nageishi Y (1982) The concept of uncertainty in animal experiments using aversive stimulation. Psychol Bull 91:573-588. CrossRef

Johnson JE (1973) Effects of accurate expectations about sensations on the sensory and distress components of pain. J Pers Soc Psychol 27:261-275. CrossRef Medline

Johnson JE, Leventhal H (1974) Effects of accurate expectations and behavioral instructions on reactions during a noxious medical examination. J Pers Soc Psychol 29:710-718. CrossRef Medline

Jones A, Bentler PM, Petry G (1966) The reduction of uncertainty concerning future pain. J Abnorm Psychol 71:87-94. CrossRef Medline

Keay KA, Bandler R (2002) Distinct central representations of inescapable and escapable pain: observations and speculation. Exp Physiol 87:275-279. CrossRef Medline

Keltner JR, Furst A, Fan C, Redfern R, Inglis B, Fields HL (2006) Isolating the modulatory effect of expectation on pain transmission: a functional magnetic resonance imaging study. J Neurosci 26:4437-4443. CrossRef Medline

Klucharev V, Hytönen K, Rijpkema M, Smidts A, Fernández G (2009) Reinforcement learning signal predicts social conformity. Neuron 61: 140-151. CrossRef Medline

Kong J, Gollub RL, Polich G, Kirsch I, Laviolette P, Vangel M, Rosen B, Kaptchuk TJ (2008) A functional magnetic resonance imaging study on the neural mechanisms of hyperalgesic nocebo effect. J Neurosci 28:13354-13362. CrossRef Medline

Koyama T, McHaffie JG, Laurienti PJ, Coghill RC (2005) The subjective experience of pain: where expectations become reality. Proc Natl Acad Sci U S A 102:12950-12955. CrossRef Medline 
Krummenacher P, Candia V, Folkers G, Schedlowski M, Schönbächler G (2010) Prefrontal cortex modulates placebo analgesia. Pain 148: 368-374. CrossRef Medline

Langford DJ, Crager SE, Shehzad Z, Smith SB, Sotocinal SG, Levenstadt IS, Chanda ML, Levitin DJ, Mogil JS (2006) Social modulation of pain as evidence for empathy in mice. Science 312:1967-1970. CrossRef Medline

Leknes S, Tracey I (2008) A common neurobiology for pain and pleasure. Nat Rev Neurosci 9:314-320. CrossRef Medline

Leventhal H, Brown D, Shacham S, Engquist G (1979) Effects of preparatory information about sensations, threat of pain, and attention on cold pressor distress. J Pers Soc Psychol 37:688-714. CrossRef Medline

Lidstone SC, de la Fuente-Fernández R, Stoessl AJ (2005) The placebo response as a reward mechanism. Semin Pain Med 3:37-42. CrossRef

Linnman C, Moulton EA, Barmettler G, Becerra L, Borsook D (2012) Neuroimaging of the periaqueductal gray: state of the field. Neuroimage 60: 505-522. CrossRef

Lovick TA (2008) Pronociceptive action of cholecystokinin in the periaqueductal grey: a role in neuropathic and anxiety-induced hyperalgesic states. Neurosci Biobehav Rev 32:852-862. CrossRef Medline

Lumb BM (2004) Hypothalamic and midbrain circuitry that distinguishes between escapable and inescapable pain. News Physiol Sci 19:22-26. CrossRef Medline

Miller RR, Greco C, Vigorito M, Marlin NA (1983) Signaled tailshock is perceived as similar to a stronger unsignaled tailshock: implications for a functional analysis of classical conditioning. J Exp Psychol Anim Behav Process 9:105-131. CrossRef Medline

Mineka S, Hendersen RW (1985) Controllability and predictability in acquired motivation. Annu Rev Psychol 36:495-529. CrossRef Medline

Montgomery GH, Kirsch I (1997) Classical conditioning and the placebo effect. Pain 72:107-113. CrossRef Medline

Morgan MM, Gold MS, Liebeskind JC, Stein C (1991) Periaqueductal gray stimulation produces a spinally mediated, opioid antinociception for the inflamed hindpaw of the rat. Brain Res 545:17-23. CrossRef Medline

Morrison I, Downing PE (2007) Organization of felt and seen pain responses in anterior cingulate cortex. Neuroimage 37:642-651. CrossRef Medline

Morton DL, El-Deredy W, Watson A, Jones AK (2010) Placebo analgesia as a case of a cognitive style driven by prior expectation. Brain Res 1359:137141. CrossRef Medline

O’Doherty JP, Hampton A, Kim H (2007) Model-based fMRI and its application to reward learning and decision making. Ann N Y Acad Sci 1104: 35-53. CrossRef Medline

Olsson A, Phelps EA (2007) Social learning of fear. Nat Neurosci 10:10951102. CrossRef Medline

Overmier J, Wielkiewicz RM (1983) On unpredictability as a causal factor in "learned helplessness"? Learn Motiv 14:324-337. CrossRef

Ploghaus A, Tracey I, Gati JS, Clare S, Menon RS, Matthews PM, Rawlins JN (1999) Dissociating pain from its anticipation in the human brain. Science 284:1979-1981. CrossRef Medline

Ploghaus A, Narain C, Beckmann CF, Clare S, Bantick S, Wise R, Matthews PM, Rawlins JN, Tracey I (2001) Exacerbation of pain by anxiety is associated with activity in a hippocampal network. J Neurosci 21:98969903. Medline

Ploghaus A, Becerra L, Borras C, Borsook D (2003) Neural circuitry underlying pain modulation: expectation, hypnosis, placebo. Trends Cogn Sci 7:197-200. CrossRef Medline

Ploner M, Lee MC, Wiech K, Bingel U, Tracey I (2010) Prestimulus functional connectivity determines pain perception in humans. Proc Natl Acad Sci U S A 107:355-360. CrossRef Medline
Porro CA, Baraldi P, Pagnoni G, Serafini M, Facchin P, Maieron M, Nichelli P (2002) Does anticipation of pain affect cortical nociceptive systems? J Neurosci 22:3206-3214. Medline

Preuschoff K, Bossaerts P, Quartz SR (2006) Neural differentiation of expected reward and risk in human subcortical structures. Neuron 51:381390. CrossRef Medline

Price DD (2000) Psychological and neural mechanisms of the affective dimension of pain. Science 288:1769-1772. CrossRef Medline

Price DD, McGrath PA, Rafii A, Buckingham B (1983) The validation of visual analogue scales as ratio scale measures for chronic and experimental pain. Pain 17:45-56. CrossRef Medline

Reynolds DV (1969) Surgery in the rat during electrical analgesia induced by focal brain stimulation. Science 164:444-445. CrossRef Medline

Salomons TV, Johnstone T, Backonja MM, Shackman AJ, Davidson RJ (2007) Individual differences in the effects of perceived controllability on pain perception: critical role of the prefrontal cortex. J Cogn Neurosci 19:993-1003. CrossRef Medline

Sawamoto N, Honda M, Okada T, Hanakawa T, Kanda M, Fukuyama H, Konishi J, Shibasaki H (2000) Expectation of pain enhances responses to nonpainful somatosensory stimulation in the anterior cingulate cortex and parietal operculum/posterior insula: an event-related functional magnetic resonance imaging study. J Neurosci 20:7438-7445. Medline

Scott DJ, Stohler CS, Egnatuk CM, Wang H, Koeppe RA, Zubieta JK (2007) Individual differences in reward responding explain placebo-induced expectations and effects. Neuron 55:325-336. CrossRef Medline

Seligman ME, Binik YM (1977) The safety-signal hypothesis. In: OperantPavlovian interactions (Davis H, Hurwitz HMB, eds), pp 165-187. Hillsdale, NJ: Erlbaum.

Seymour B, Dolan RJ (2012) Emotion, motivation and pain. In: Wall and Melzack's textbook of pain, Ed 6. New York: Elsevier.

Singer T, Seymour B, O’Doherty J, Kaube H, Dolan RJ, Frith CD (2004) Empathy for pain involves the affective but not sensory components of pain. Science 303:1157-1162. CrossRef Medline

Tomasello M (1999) The human adaptation for culture. Ann Rev Anthropol 28:509-529. CrossRef

Tracey I (2010) Getting the pain you expect: mechanisms of placebo, nocebo and reappraisal effects in humans. Nat Med 16:1277-1283. CrossRef Medline

Vanegas H, Schaible HG (2004) Descending control of persistent pain: inhibitory or facilitatory? Brain Res Brain Res Rev 46:295-309. CrossRef Medline

Voudouris NJ, Peck CL, Coleman G (1990) The role of conditioning and verbal expectancy in the placebo response. Pain 43:121-128. CrossRef Medline

Wager TD, Rilling JK, Smith EE, Sokolik A, Casey KL, Davidson RJ, Kosslyn SM, Rose RM, Cohen JD (2004) Placebo-induced changes in FMRI in the anticipation and experience of pain. Science 303:1162-1167. CrossRef Medline

Wager TD, Atlas LY, Leotti LA, Rilling JK (2011) Predicting individual differences in placebo analgesia: contributions of brain activity during anticipation and pain experience. J Neurosci 31:439-452. CrossRef Medline

White DJ, Galef BG (1998) Social influence on avoidance of dangerous stimuli by rats. Animal Learn Behav 26:433-438. CrossRef

Yuille A, Kersten D (2006) Vision as Bayesian inference: analysis by synthesis? Trends Cogn Sci 10:301-308. CrossRef Medline

Zubieta J, Stohler CS (2009) Neurobiological mechanisms of placebo responses. Ann N Y Acad Sci 1156:198-210. CrossRef Medline 